\title{
The convolution of time and weathering intensity on the fate of runoff-to-groundwater partitioning in the Island of Hawai'i
}

\author{
A. PereZ-Fodich ${ }^{1}$,L.A. DerRY ${ }^{2,3}$ \\ ${ }^{1}$ Department of Geology, University of Chile, Santiago, Chile \\ (aliperez@uchile.cl) \\ ${ }^{2}$ Department of Earth and Atmospheric Sciences, Cornell \\ University, Ithaca, NY \\ ${ }^{3}$ Université de Paris, Institut de Physique du Globe de Paris, \\ CNRS, F-75005, Paris, France
}

Runoff-to-groundwater partitioning changes as a function of the substrate age and the degree of regolith development in the Island of Hawai'i. We have investigated this relationship by modeling watershed-scale hydrodynamic properties in catchments with varying weathering degrees as a function of substrate age and climate. Initial high porosity and hydraulic conductivity characterize the younger and drier volcanoes in the Island of Hawaii: most of the rainfall infiltrates directly to the groundwater system, which results in limited surface runoff often as ephemeral streams. On the other hand, the more developed older and wetter areas show increasing runoff, incision, and perennial discharge. We hypothesize that runoff-to-groundwater partitioning is a function of the timeintegrated weathering history, as hydrodynamic properties at the watershed-scale-e.g. hydraulic conductivity-change with time and weathering degree on these basaltic catchments.

To test this hypothesis, we calculated hydraulic conductivity and aquifer depth using the recession flow analysis method[1] on perennial catchments hosted on lava flows of different ages and climates across the Island of Hawaii. Besides, we investigated the sub-daily recession behavior in ephemeral streams in the young slopes of Mauna Loa. Our results indicate that hydraulic conductivity on the younger perennial catchments spans between 3 to 6 orders of magnitude higher compared to their more weathered (older/wetter) counterparts. The analysis from the ephemeral streams shows that stream recession increases by one order of magnitude, as the portion of lava flows older than 5,000 years increases just by $15 \%$. Thus, pedogenesis and chemical depletion through weathering appear to drive the reduction of permeability in this volcanic landscape at millenial timescales. Our results emphasize the role of weathering and direct groundwater discharge in the landscape evolution of volcanic islands.

[1] Brutsaert, Nieber. (1977). WRR. 13, 637-644. 